\title{
Association between contraceptive discontinuation and pregnancy intentions in Guatemala ${ }^{1}$
}

\author{
Janine L. Barden-O'Fallon, ${ }^{2}$ Ilene S. Speizer, ${ }^{2,3}$ and Justin S. White ${ }^{2,4}$
}

Suggested citation

Barden-O'Fallon JL, Speizer IS, White JS. Association between contraceptive discontinuation and pregnancy intentions in Guatemala. Rev Panam Salud Publica. 2008; 23(6):410-7.

ABSTRACT Objectives. To determine whether contraceptive discontinuation is associated with pregnancies that are conceived earlier than desired (mistimed) or are not wanted at the time of conception (unwanted).

Methods. Data were obtained from the 2002 Guatemala National Maternal and Child Health Survey. Pregnancies within the three years prior to and at the time of the survey (April 1999-November 2002) were classified as either "intended," "mistimed," or "unwanted." The key independent variable was whether the woman had used contraception within 12 months of the pregnancy and, for those who had used it, the reason for discontinuation (either to get pregnant or for another reason). A multinomial logistic analysis was used to determine the degree of association of discontinuation with pregnancy intentions.

Results. One of every five mistimed pregnancies and one of every six unwanted pregnancies followed discontinuations that were for reasons other than to become pregnant (e.g., contraceptive failure, side effects, and health concerns). Discontinuations for reasons other than to become pregnant were shown to be positively and significantly associated with a reported mistimed pregnancy (coefficient $=2.15$; standard error $=0.27$ ) or unwanted pregnancy $(2.68$; 0.37 ) compared to an intended pregnancy. Pregnancies preceded by discontinuations for reasons other than to become pregnant were also more likely to be reported as mistimed or unwanted than pregnancies of women who were not using contraception during the year prior to pregnancy.

Conclusions. There is a need to increase contraceptive continuation. Any program should include an increased effort to reduce contraceptive failure and better address the side effects and the health concerns that women have that can lead to discontinuation. Non-users who want to delay or limit births should also be identified and targeted for outreach in order to reduce unintended pregnancies.

Keywords Contraception; pregnancy, unplanned; pregnancy, unwanted; Guatemala.

1 A version of this paper was presented at the 134 th Annual Meeting of the American Public Health Association, 4-8 November 2006, Boston, Massachusetts, United States of America.

2 MEASURE Evaluation Project, Carolina Population Center, University of North Carolina at Chapel Hill, Chapel Hill, North Carolina, United States. Send correspondence and reprint requests to: Janine Barden-O'Fallon, MEASURE Evaluation
Project, 206 W. Franklin St. CB\# 8120, Chapel Hill, NC 27516, USA; fax: (919) 966-2391; email: bardenof@email.unc.edu.

3 Department of Maternal and Child Health, University of North Carolina at Chapel Hill, School of Public Health, Chapel Hill, North Carolina, United States.

4 Health Services and Policy Analysis Program, University of California at Berkeley, Berkeley, California, United States
The consequences of unintended pregnancies are of major public health concern. Each year, 80 million women worldwide have unwanted or unintended pregnancies. The result is 46 million induced abortions, 19 million 
of which are considered unsafe $(1,2)$. The complications of unsafe abortions contribute to maternal morbidity and are responsible for 68000 maternal deaths annually (3). Unintended pregnancies carried to term are also likely to lead to adverse pregnancy outcomes, such as preterm birth, low birth weight, and small size for gestational age (4). In some cases, unintended pregnancies have also been shown to be associated with poor early childhood health $(5,6)$.

Unintended pregnancies are the consequence of multiple factors including non-use of contraception among women who do not want to get pregnant, contraceptive failure among users of contraception, and contraceptive discontinuation, that is, the starting and stopping of contraceptive use. A study in the United States estimated that in 1988, while $53 \%$ of unintended pregnancies were to women who were not using contraception, the remaining $47 \%$ of unintended pregnancies were to users of reversible methods who experienced contraceptive failure or discontinuation (7).

Women use contraception for a variety of biological, individual, and social reasons over the course of their reproductive lives. Some women use contraception to avoid a premarital or extramarital pregnancy, while others use contraception to space births or to prevent additional births once they have attained their desired family size. Societies in which large numbers of women use family planning to control fertility, have fewer unsafe abortions and longer birth intervals, and consequently, lower rates of maternal mortality and morbidity and infant mortality (8). However, even in countries with a low desired family size and high use of contraception, unintended pregnancies are still common (e.g., in the United States, 35\% of pregnancies were considered unintended in the 2002 National Survey of Family Growth) (9). In some settings, the nonuse of family planning has been shown to contribute to the largest share of unintended pregnancies (10). Other research demonstrates that contraceptive failure and discontinuation also contribute to high unwanted fertility levels. For example, Blanc et al. used demographic and health survey data from 15 developing countries to estimate that total unwanted fertility rates would be $44 \%-81 \%$ lower if contraceptive failure or discontinuation (for reasons other than desiring a child) had not occurred (11). Guatemala, the country with the smallest predicted effect, would see the total unwanted fertility rate reduced by $44 \%$ if contraceptive failure and discontinuation were averted, while the other countries could see a drop of $50 \%$. Such findings have led some researchers to encourage policy makers and program managers to focus on improving contraceptive continuation rather than trying to convince nonusers to become users $(11,12)$.

Clearly, non-use of contraception and contraceptive discontinuation and failure are important contributors to unintended pregnancies. Most studies examine one or the other contributor (non-use or contraceptive discontinuation and failure), with less attention to the joint contributions to unintended pregnancy. Moreover, few studies on unintended pregnancy risk include use and discontinuation status in the models. The research has generally shown that women are more likely to experience mistimed pregnancies if they are younger, more educated, not in union, have a short birth interval, or have a higher number of living children (13). The same is true for women experiencing unwanted pregnancies, with the exception that they tend to be older and less educated (13).

Studies on non-use of family planning and contraceptive discontinuation have demonstrated a number of sociodemographic factors associated with these outcomes. Factors associated with non-use of contraception include education, residence, socioeconomic status, and fertility goals. Women who are less educated, live in rural areas, are poorer, opposed to contraceptive use, or desire more children are less likely to be using contraception $(14,15)$. Studies of factors associated with contraceptive discontinuation find significant effects of age, number of living children/parity, and fertility goals. Young women, women who have more children, and women who intend to space births, rather than limit births, are significantly more likely to discontinue, than all others (16). Socioeconomic factors, such as education, residence, and socioeconomic status, tend to be less strongly associated with discontinuation $(16,17)$. The type of contraceptive method also relates to the rate of discontinuation (11). Women using the user-dependent contraceptive methods, such as the pill, injections, condoms, and withdrawal, are more likely to discontinue than are those using non-user-dependent methods, such as the intrauterine device (IUD) and implants.

Another key factor for the discontinuation or non-use of contraception is fear of experiencing side effects $(18,19)$. This often correlates with the method being used, particularly hormonal methods. Finally, a smaller body of research indicates that a woman's individual characteristics, including motivations to avoid pregnancy, self-efficacy, and autonomy, are associated with her adoption and continued effective use of contraception (20).

The aim of this paper is to determine the influence of discontinuation on unintended pregnancy risk among women in Guatemala. By including women who are also non-users of family planning, we simultaneously examined the contribution of both non-use and discontinuation on unintended pregnancy risk. In particular, we were interested in whether discontinuation for reasons other than to become pregnant-side effects, health concerns, or contraceptive failure-was associated with a higher likelihood of unwanted or mistimed pregnancies, than was discontinuation to get pregnant. Additionally, we examined the relationship between non-use of contraception and pregnancy intentions. Included in the analyses are individual-level factors related to experiencing an unwanted or mistimed pregnancy, such as age, education, union status, and birth number, as well as other specific sociodemographic characteristics. 


\section{STUDY CONTEXT}

The study took place in Guatemala where the total fertility rate in 2002 was 4.4. Among women who gave birth in the three years prior to the 2002 National Maternal and Child Health Survey (Encuesta Nacional de Salud Materno Infantil, ENSMI), 16.5\% reported the birth as mistimed and $15 \%$ as unwanted (21). For the same year, contraceptive use was correspondingly low, with $43 \%$ of couples reporting current use of any method to prevent pregnancy and 34\% reporting current use of a modern method, i.e., sterilization, injectable, oral contraceptive pill, IUD, or condom. The remaining women were using traditional methods, such as periodic abstinence or withdrawal. Sterilization is the most common method of contraception, followed by injectables and traditional methods. In the 2002 survey, about $36 \%$ of users reported discontinuing contraception during the first 12 months of use. Among these, 20.5\% discontinued in order to become pregnant. Side effects were the most often reported reason for discontinuation ( $21 \%$ ), accounting for over one-third of discontinuations among women using oral contraceptive pills, injectables, and the IUD. Method failure was responsible for an additional $17 \%$ of discontinuations, and health concerns, almost $9 \%$. A number of other reasons, such as wanting a more effective method $(8.5 \%)$, having infrequent sex $(7.6 \%)$, or finding the method inconvenient to use $(3.9 \%)$, accounted for the rest of discontinuations.

\section{MATERIALS AND METHODS}

Data from the 2002 Guatemala National Maternal and Child Health Survey (21) were analyzed. The survey used a multistage sampling design in which the primary sampling units (PSUs) were census segments. The probability of selection of a PSU was proportional to size. In each randomly selected PSU, 30 households were randomly selected. Female and male samples were independent; only one eligi- ble woman or one eligible man was interviewed in each selected household. Eligibility was defined as being a woman of 15-49 years of age or a man of 15-59 years. Participants were interviewed in or around their homes. Women were interviewed by female interviewers, and men, by male interviewers. Prior to beginning the survey, interviewers requested verbal consent from all eligible participants. All participants were assured that they did not have to participate in the interview and could refuse to answer any of the questions. Response rates were high: $94 \%$ of eligible women and $80 \%$ of eligible men participated. A total of 9155 women and 2538 men participated in the survey (data from the independent men's survey are not included in this paper). The data were weighted by the number of eligible respondents in the household.

This analysis focuses on women who were pregnant at the time of the interview or had experienced a live birth in the three years prior. Stillbirths and pregnancy losses were not included given that pregnancy intention data were collected only for live births and that calendar data do not distinguish between induced or spontaneous abortions (while induced abortions are generally unwanted, the same cannot be said of spontaneous abortions). Of all women in the Guatemala survey, 4118 were either pregnant and/or had had a live birth in the three years prior. Some women contributed multiple observations (birth(s) and a current pregnancy) within the three years prior to the survey, though no woman contributed more than three observations. The 4118 participants produced a sample totaling 4633 live births in the three years prior and 767 pregnancies at the time of the interview. Thus, a total of 5400 observations are used for the analysis of the association between contraceptive use/discontinuation and intentionality of the pregnancy that followed.

The survey questionnaire covered a variety of maternal and child health topics, including pregnancy and childbearing; family planning; access to re- productive health care services; sexual behavior, knowledge, and attitudes; infant mortality and morbidity; breastfeeding and child nutrition; immunizations; attitudes and knowledge about HIV / AIDS; and family violence. The dependent variable for the analysis relates to the intentionality of the current pregnancy and of each birth in the three years prior to the survey. For each birth and pregnancy within the study timeframe, women were asked whether they had wanted to become pregnant at that time, had wanted to wait until a later time, or had not wanted any (more) children at all. Pregnancies were classified as "wanted" if the woman reported having wanted the pregnancy at the time; "mistimed" if she reported having wanted to wait to become pregnant; or "unwanted" if she reported not having wanted any (more) children at the time she became pregnant.

The key independent variable of interest was whether the woman discontinued contraceptive use at any time during the 12 months preceding the current pregnancy or a pregnancy that produced a live birth in the three years prior. The contraceptive use data were collected through the implementation of the contraceptive calendar, a module designed to collect a monthly record of fertility and contraceptive use for the five years preceding the date of the interview (1997-2002). Based on the month of interview, women were asked about the preceding five-year period; for example, a woman who was interviewed in April 2002 would be asked to complete the calendar for the period since April 1997. For each month, the information collected in the calendar included whether contraception was used, the type of contraception used, whether a pregnancy occurred, result of the pregnancy (live birth, abortion, or stillbirth), and marital status. If contraception was discontinued, respondents were asked to provide the main reason for the discontinuation, thus a single reason is recorded in the calendar (for more on the calendar approach, see Blanc et al.) (11). Contraceptive discontinuation is considered to occur 
when a woman reports no use of any contraceptive method after at least one month (one episode) of use. If a respondent switches methods, it is not considered a discontinuation if the episodes of use are continuous. Women may contribute multiple discontinuations over the course of a fiveyear period.

For this analysis, we were interested in the pregnancies that followed contraceptive discontinuation. Specifically, we were interested in those pregnancies that took place while contraception was being used (contraceptive failure) and those that followed at least one episode of contraceptive use, where the pregnancy occurred immediately after discontinuation or up to one year later. Therefore, the analysis covered contraceptive failures as well as intentional discontinuations. Because the analysis is limited to births occurring within the previous three years, the longest possible birth history would be a birth occurring three years prior to the survey, following a full-term pregnancy of nine months that was preceded by a one year period of non-use and at least one month of contraceptive use (in other words, a contraceptive discontinuation occurring 12 months prior to the pregnancy). Hence, four years and 10 months of the calendar data were used. Limiting the analysis to births within the previous three years, therefore, limited the problem of left censoring of the data. Contraceptive use/discontinuation status within 12 months of the pregnancy was coded as a non-user prior to pregnancy, a user who intentionally discontinued in order to become pregnant, or a user who discontinued for any other reason or experienced contraceptive failure.

The analysis included a number of other independent variables: age, grouped into four categories (15-19 years of age, 20-29 years, 30-39 years, and 40-49 years); residence, coded as urban or rural; highest level of education, defined as none, primary, or secondary and higher; religion, categorized as Catholic, evangelical/ protestant, or other/none; and ethnic- ity, coded as indigenous or ladino, the Guatemalan term for the main ethnicity (mestizo). Socioeconomic status (SES) was coded as low, medium, or high, based on an unweighted count of the number of household services and durable goods in the woman's home. Included in the SES calculation were the number of rooms in the home, type of cooking fuel used, type of toilet, and whether or not the home had electricity and/or a television. Also included in the analysis was whether the woman was currently pregnant (yes/ no) and her marital status (married/in union or unmarried/not in union). The birth order of live births and current pregnancies was used for all birth-level analyses and coded as a first, second-third, fourth-fifth, or sixth or higher.

All data were weighted and the analyses accounted for clustering in the survey design. Multivariate multinomial logistic regression analyses of pregnancy intention (intended vs. mistimed vs. unwanted) were performed on the pregnancy/birth sample. The analyses included the key independent variable contraceptive use/discontinuation and controlled for all other variables. The analyses were run using STATA version 9.2 (STATA Corp., College Station, Texas, United States).

\section{RESULTS}

Of the 9152 women in the total sample (three cases were dropped due to missing information on religion), 7212 women had ever given birth or were currently pregnant and of these, 4118 women had given birth within the last three years or were currently pregnant. Table 1 presents demographic characteristics of the total sample compared to those of the study samplethe women who had recently given birth or were currently pregnant. The table shows that the women in the study sample were more likely to be in the 15-19 or the 20-29 age group, to reside in a rural area, and to have little or no education. A higher percentage of the study sample was indigenous and in the low or medium socioeconomic group.

When the study sample was converted to a sample of recent births/ current pregnancies, there were a total of 5400 observations. Of these, there were $4633(85.8 \%)$ births that occurred during the three years prior and 767 (14.2\%) current pregnancies. The overwhelming majority of women $(79.4 \%)$ were non-users of contraception during the 12 months prior to the pregnancy, as shown in Table 2. Of the pregnancies, 9\% occurred in women who had been using contraception in the 12 months prior, but discontinued to get pregnant; and $11.5 \%$ occurred in users who discontinued for another reason (e.g., contraceptive failure, side effects, health concerns, etc.). Among the current pregnancies, $16 \%$ occurred in users who discontinued for another reason. Among all women who were using contraception in the year before the pregnancy, the single main reason for discontinuation was the desire to become pregnant (45\%); however, contraceptive failure accounted for $32 \%$ of discontinuations, and side effects $(8 \%)$ and health concerns (3\%) combined accounted for $11 \%$. Table 2 also shows that the overwhelming majority of the pregnancies and recent births occurred when the mother was either married or in union.

Table 2 also shows the women's intention. Most pregnancies were reported as intended at the time of pregnancy, although one-third were unintended, that is, either mistimed or unwanted. Women reporting the intention of a current pregnancy were more likely to report the pregnancy as mistimed, than unwanted, as compared to the women reporting on births in the three years prior.

The results of a cross-tabulation of discontinuation status and reported intendedness of the pregnancy are shown in Table 3. A test of equivalence between column distributions using Pearson's chi-square test shows that discontinuation prior to pregnancy varies significantly by intention status of the pregnancy. Overall, one of every five mistimed pregnancies and one of every six unwanted preg- 
TABLE 1. Demographic characteristics of women in the 2002 Guatemala National Maternal and Child Health Survey and study sample

\begin{tabular}{|c|c|c|}
\hline Demographic characteristic & $\begin{array}{c}\text { Total sample } \\
\left(n^{\mathrm{a}}=9152\right) \\
\%^{\mathrm{b}}\end{array}$ & $\begin{array}{l}\text { Live birth in the three years } \\
\text { prior or currently pregnant } \\
\left(n^{\mathrm{a}}=4118\right) \\
\% \%^{\mathrm{b}}\end{array}$ \\
\hline \multicolumn{3}{|l|}{ Years of age } \\
\hline $15-19$ & 23.7 & 12.5 \\
\hline $20-29$ & 33.2 & 53.7 \\
\hline $30-39$ & 23.8 & 27.0 \\
\hline $40-49$ & 19.2 & 6.9 \\
\hline \multicolumn{3}{|l|}{ Residence } \\
\hline Rural & 57.4 & 65.6 \\
\hline Urban & 42.6 & 34.4 \\
\hline \multicolumn{3}{|l|}{ Level of education } \\
\hline None & 25.5 & 33.6 \\
\hline Primary & 44.4 & 48.6 \\
\hline Secondary and higher & 30.1 & 17.9 \\
\hline \multicolumn{3}{|l|}{ Religion } \\
\hline Catholic & 51.3 & 47.5 \\
\hline Evangelical/protestant & 35.8 & 36.4 \\
\hline None/other & 12.9 & 16.1 \\
\hline \multicolumn{3}{|l|}{ Indigenous } \\
\hline No & 69.3 & 60.5 \\
\hline Yes & 30.7 & 39.5 \\
\hline \multicolumn{3}{|l|}{ Socioeconomic status } \\
\hline Low & 20.9 & 32.4 \\
\hline Medium & 34.8 & 40.9 \\
\hline High & 44.3 & 26.7 \\
\hline \multicolumn{3}{|l|}{ Parity } \\
\hline 0 & 32.7 & 4.6 \\
\hline $1-2$ & 24.4 & 39.7 \\
\hline $3-4$ & 21.6 & 26.8 \\
\hline $5+$ & 21.3 & 28.9 \\
\hline \multicolumn{3}{|l|}{ Currently pregnant } \\
\hline No & 92.7 & 79.7 \\
\hline Unsure & 0.6 & 0.9 \\
\hline Yes & 6.7 & 19.5 \\
\hline
\end{tabular}

a Unweighted.

${ }^{\mathrm{b}}$ Weighted for clustering in survey design.

nancies followed discontinuations for reasons other than to become pregnant. Even among pregnancies that were wanted, almost $8 \%$ followed a discontinuation for reasons other than to become pregnant. A greater percentage of women were using contraception prior to current pregnancies than prior to live births in the last three years (Table 2). Discontinuation was also more common for current pregnancies than for live births in the three years prior. For current pregnancies, discontinuations for reasons other than to become pregnant occurred prior to almost $10 \%$ of intended pregnancies, 30\% of mistimed pregnancies, and $28 \%$ of unwanted pregnancies. Notably, very few current pregnancies that were mistimed or unwanted followed discontinuation to get pregnant.

Table 4 shows the results of the multinomial logistic regression of pregnancy intention by contraceptive discontinuation behavior. Analyses were performed on the two groups combined (births in the three years prior and current pregnancies), as well as for each group separately. The results of the combined model were similar to the separate models, with minor exceptions (separate models not shown).

Table 4 shows that births or pregnancies that followed from discontinuation, for reasons other than to become pregnant, were significantly more likely to be reported as mistimed (coefficient: 2.15; standard error: 0.27 ) or unwanted $(2.68 ; 0.37)$, than intended, as compared to births or pregnancies where contraception was discontinued in order to become pregnant. Pregnancies and births where the woman was not using contraception (non-users) were also significantly more likely to be reported as mistimed or unwanted than intended as compared to pregnancies of women who discontinued to become pregnant. Furthermore, mistimed and unwanted pregnancies were more likely to be reported by women who discontinued for reasons other than to become pregnant than by women who were non-users prior to the pregnancy (results not shown in table).

A small number of other independent variables are significantly related to the report of a mistimed or unwanted pregnancy, most notably, birth order. For both the comparison between mistimed and intended and between unwanted and intended, the higher order births (or current pregnancies) were significantly more likely to be reported as mistimed or unwanted than intended.

Also significant was union status at the time of pregnancy; pregnancies or births occurring to women who were married or in union were significantly less likely to be reported as mistimed, and much less likely to be reported as unwanted, compared to pregnancies or births by single women. Women who were currently pregnant were significantly less likely to report a pregnancy as unwanted compared to intended than were women who were not currently pregnant; there was no difference in current pregnancies and live births in three years prior when comparing mistimed to intended pregnancies.

Level of education also had a significant relationship to birth intentions. Pregnancies in mothers with primary education or less were more likely to be reported as unwanted compared to intended than those of women with secondary level education or higher. Conversely, women of higher SES 
TABLE 2. Characteristics of the study sample comprised of live births in the three years prior to the survey and pregnancies at the time of the survey (current pregnancies). Guatemala National Maternal and Child Health Survey, 2002

\begin{tabular}{|c|c|c|c|}
\hline Characteristic & $\begin{array}{l}\text { Live births in the } \\
\text { three years prior and } \\
\text { current pregnancies } \\
\left(n^{\mathrm{a}}=5400\right) \\
\%^{\mathrm{b}}\end{array}$ & $\begin{array}{c}\text { Live births in the } \\
\text { three years prior } \\
\left(n^{\mathrm{a}}=4633\right) \\
\%^{\mathrm{b}}\end{array}$ & $\begin{array}{c}\text { Current } \\
\text { pregnancies } \\
\left(n^{\mathrm{a}}=767\right) \\
\%^{\mathrm{b}}\end{array}$ \\
\hline \multicolumn{4}{|l|}{ Marital status at time of pregnancy } \\
\hline Not married or in union & 8.0 & 8.4 & 6.2 \\
\hline Married or in union & 92.0 & 91.6 & 93.8 \\
\hline \multicolumn{4}{|l|}{ Current pregnancy } \\
\hline No & 84.8 & $N A^{c}$ & NA \\
\hline Yes & 15.2 & & \\
\hline \multicolumn{4}{|l|}{$\begin{array}{l}\text { Contraceptive status within } 12 \text { months } \\
\text { of pregnancy }\end{array}$} \\
\hline Non-user & 79.4 & 80.3 & 74.6 \\
\hline Discontinued to get pregnant & 9.1 & 9.1 & 9.1 \\
\hline Discontinued for another reason & 11.5 & 10.7 & 16.3 \\
\hline \multicolumn{4}{|l|}{ Intention status of birth/pregnancy } \\
\hline Intended & 66.9 & 67.1 & 65.7 \\
\hline Mistimed & 18.3 & 17.3 & 23.5 \\
\hline Unwanted & 14.8 & 15.6 & 10.8 \\
\hline \multicolumn{4}{|l|}{$\begin{array}{l}\text { a Unweighted. } \\
\text { b Weighted for clustering in survey design. } \\
\text { ' Not applicable. }\end{array}$} \\
\hline
\end{tabular}

\begin{tabular}{|c|c|c|c|}
\hline & \multicolumn{3}{|c|}{ Intention Status } \\
\hline & $\begin{array}{l}\text { Intended } \\
\%{ }^{b}\end{array}$ & $\begin{array}{l}\text { Mistimed } \\
\%^{\mathrm{b}}\end{array}$ & $\begin{array}{l}\text { Unwanted } \\
\%^{\mathrm{b}}\end{array}$ \\
\hline \multicolumn{4}{|l|}{$\begin{array}{l}\text { All births in three years prior and } \\
\text { current pregnancies }\left(n^{\mathrm{a}}=5400\right)^{\mathrm{c}}\end{array}$} \\
\hline Non-user & 80.3 & 74.8 & 81.1 \\
\hline Discontinued to get pregnant & 12.0 & 4.2 & 1.9 \\
\hline Discontinued for another reason & 7.7 & 21.1 & 17.0 \\
\hline \multicolumn{4}{|l|}{ All births three years prior $\left(n^{\mathrm{a}}=4633\right)^{\mathrm{c}}$} \\
\hline Non-user & 80.8 & 76.5 & 82.1 \\
\hline Discontinued to get pregnant & 11.9 & 4.5 & 2.2 \\
\hline Discontinued for another reason & 7.3 & 18.9 & 15.7 \\
\hline \multicolumn{4}{|l|}{ Current pregnancies $\left(n^{\mathrm{a}}=767\right)^{\mathrm{c}}$} \\
\hline Non-user & 77.6 & 67.5 & 72.4 \\
\hline Discontinued to get pregnant & 12.9 & 2.7 & 0.0 \\
\hline Discontinued for another reason & 9.6 & 29.9 & 27.6 \\
\hline
\end{tabular}

\footnotetext{
a Unweighted.

${ }^{b}$ Weighted for clustering in survey design.

${ }^{c} P<0.001$.
}

were significantly more likely to report their pregnancy as mistimed or unwanted compared to intended than women of low SES.

\section{DISCUSSION}

The main objective of this paper was to learn whether discontinuation for reasons other than the desire to get pregnant-such as contraceptive failure, side effects, or health concerns-is associated with a higher likelihood of reporting recent pregnancies as unintended or mistimed. Only a fraction of Guatemalan women who use contraception have firm fertility desires and discontinue in order to become pregnant. In addition, a large percentage of non-users report their births or pregnancies as unintended (mistimed/ unwanted). The analysis showed that mistimed and unwanted births are relatively common, and that discontinuing the use of contraception for reasons other than to become pregnant is significantly associated with reporting mistimed or unwanted pregnancies, even after controlling for other factors associated with intention status. Though non-users of contraception also contribute to mistimed and unwanted pregnancies, all else being equal, women who have discontinued for reasons other than to become pregnant are more likely to report pregnancies as mistimed or unwanted than non-users. Other than contraceptive use status prior to the pregnancy, the study identified additional factors strongly and significantly associated with pregnancy intention, most notably birth order and marital status. This is consistent with previously presented evidence (13).

Some data and analysis issues present potential limitations to the study. Foremost is that the data were collected retrospectively, that is, sometime after the birth of the child. It is unknown to what extent a woman's perception of the pregnancy could change over time, nor to what extent the reporting of pregnancy intentions would change as a result. Reporting error in the contraceptive calendar is likely to be another source of recall bias, because respondents were asked to report contraceptive use for each month over the past five years. Strickler et al. found that while calendar data appear to be reliable at the aggregate level, the reported reason for discontinuation is potentially the most problematic information obtained through the implementation of this in- 
TABLE 4. Coefficients from multinomial logistic regressions of factors associated with intentionality of births in the three years prior and current pregnancies of study sample. ${ }^{\mathrm{a}}$ Guatemala National Maternal and Child Health Survey, 2002

\begin{tabular}{|c|c|c|c|c|}
\hline \multirow[b]{2}{*}{ Urban (vs. rural) } & \multicolumn{2}{|c|}{$\begin{array}{l}\text { Mistimed } \\
\text { vs. } \\
\text { intended }\end{array}$} & \multicolumn{2}{|c|}{$\begin{array}{l}\text { Unwanted } \\
\text { vs. } \\
\text { intended }\end{array}$} \\
\hline & 0.08 & $(0.19)$ & 0.06 & $(0.16)$ \\
\hline \multicolumn{5}{|l|}{ Age group } \\
\hline $15-19$ & 0.13 & $(0.25)$ & 0.27 & $(0.2)$ \\
\hline 20-29 (reference category) & - & - & - & - \\
\hline $30-39$ & -0.39 & $(0.15)^{b}$ & -0.12 & $(0.15)$ \\
\hline $40-49$ & -0.57 & $(0.3)$ & 0.43 & $(0.26)$ \\
\hline \multicolumn{5}{|l|}{ Education } \\
\hline None & -0.21 & $(0.24)$ & 0.71 & $(0.27)^{c}$ \\
\hline Primary & 0.10 & $(0.22)$ & 0.76 & $(0.26)^{c}$ \\
\hline Secondary and higher (reference category) & - & - & - & - \\
\hline \multicolumn{5}{|l|}{ Religion } \\
\hline Catholic (reference category) & - & - & - & - \\
\hline Protestant/evangelical & -0.20 & $(0.12)$ & -0.05 & $(0.12)$ \\
\hline None/other & 0.11 & $(0.16)$ & 0.45 & $(0.15)^{c}$ \\
\hline Indigenous (vs. not) & 0.12 & $(0.13)$ & 0.14 & $(0.13)$ \\
\hline \multicolumn{5}{|l|}{ SES } \\
\hline Low (reference category) & - & - & - & - \\
\hline Medium & -0.10 & $(0.14)$ & -0.24 & $(0.14)$ \\
\hline High & 0.63 & $(0.23)^{c}$ & 0.41 & $(0.21)^{\mathrm{b}}$ \\
\hline \multicolumn{5}{|l|}{ Birth number } \\
\hline 1st (reference category) & - & - & - & - \\
\hline $2-3$ & 0.76 & $(0.32)^{b}$ & 0.99 & $(0.2)^{d}$ \\
\hline $4-5$ & 1.11 & $(0.34)^{d}$ & 1.54 & $(0.22)^{d}$ \\
\hline $6+$ & 1.14 & $(0.43)^{c}$ & 1.86 & $(0.27)^{d}$ \\
\hline In union (vs. not) & -0.75 & $(0.27)^{\mathrm{c}}$ & -1.91 & $(0.24)^{d}$ \\
\hline Currently pregnant (vs. not) & 0.24 & $(0.15)$ & -0.4155 & $(0.17)^{b}$ \\
\hline \multicolumn{5}{|l|}{ Contraceptive use } \\
\hline Non-user & 1.37 & $(0.26)^{d}$ & 1.82 & $(0.34)^{d}$ \\
\hline Discontinued/pregnancy (reference category) & - & - & - & - \\
\hline Discontinued/other & 2.15 & $(0.27)^{d}$ & 2.68 & $(0.37)^{d}$ \\
\hline
\end{tabular}

a Total sample of births in the three years prior and current pregnancies, weighted for clustering in survey design (unweighted $n=5400)$.

${ }^{\mathrm{b}} P \leq 0.05$.

${ }^{c} P \leq 0.01$.

${ }^{d} P \leq 0.001$.

strument (22). This may be due to difficulty in remembering why episodes of contraception were stopped, especially if discontinuation occurred frequently, or perhaps, as Curtis and Blanc argue, that recording only one reason for discontinuation does not capture the entire picture of how women and their partners make the decision to stop (17). It has been noted that reasons for discontinuing contraception may not be mutually exclusive and that the degree to which a woman is motivated to avoid a pregnancy may play a key role, particularly in method failure (18). While no less salient to this study, these is- sues are somewhat mitigated in the analysis because all reasons other than the desire to become pregnant were grouped together. What is left unknown is the extent to which this type of discontinuation is due to ambivalence or more decisive action.

The final limitation of the study is that it did not account for method type, though factors that influence method also influence discontinuation (23). Moreover, method choice might be associated with strength of fertility desires at the time of use; that is, those who are the most motivated to avoid future pregnancies are most likely to use the IUD, while those who wish to merely delay a subsequent pregnancy, or are more ambivalent about their fertility, are more likely to use a userdependent method, which implies a greater risk of discontinuation.

Effective use of contraception becomes increasingly important as contraceptive prevalence increases and desired family size decreases (11). This study found that a large proportion of discontinuations preceding pregnancies were due to contraceptive failures. Assuming these women are not ambivalent users, this is a strong indication that there is a need to improve family planning services to reduce mistimed and unwanted pregnancies. Such improvements may include better counseling on methods and on how to be an effective user.

A need also exists to better address the side effects and the health concerns that can lead to discontinuation. One approach would be to improve the options for switching methods, so that women experiencing problems with a particular method can continue using contraception. Unintended pregnancies resulting from the discontinuation of contraception due to side effects or health concerns are indicative of an unmet need for a wider choice of contraceptive methods or for more information on method concerns. Another approach would be to better train health care providers so that women are matched to an appropriate method based on their fertility goals, method preferences, and previous experience with contraception. Finally, to further reduce unintended pregnancies, women who are not using contraception and who want to delay or limit births need to be identified so that the appropriate family planning services can be offered.

Acknowledgement. Support for this research was made possible by the U.S. Agency for International Development (USAID) under the terms of Cooperative Agreement GPO-A-00-03-00003-00. The opinions expressed are those of the authors and do not necessarily reflect the views of USAID or the United States Government. 


\section{REFERENCES}

1. Alan Guttmacher Institute. Sharing responsibility: women, society \& abortion worldwide. New York: Alan Guttmacher Institute; 1999.

2. Glasier A, Gülmezoglu AM, Schmid GP, Garcia Moreno C, Van Look PFA. Sexual reproductive health: A matter of life and death. Lancet. 2006;368(9547):1595-607.

3. World Health Organization. Unsafe abortionGlobal and regional estimates of the incidence of unsafe abortion and associated mortality in 2000. 4th ed. Geneva: WHO; 2004.

4. Conde-Agudelo A, Rosas-Bermúdez A, Kafury-Goeta, AC. Birth spacing and risk of adverse perinatal outcomes: a meta-analysis. JAMA. 2006;295:1809-23.

5. Marston C, Cleland J. Do unintended pregnancies carried to term lead to adverse outcomes for mother and child? An assessment in five developing countries. Popul Stud (Camb). 2003;57(1):77-93.

6. Shapiro-Mendoza C, Selwyn BJ, Smith DP, Sanderson M. Parental pregnancy intention and early childhood stunting: findings from Bolivia. Int J Epidiol. 2005;34(2):387-96.

7. Brown $\mathrm{S}$ and Eisenberg L, eds. The best intentions: unintended pregnancy and the wellbeing of children and families. Washington, DC: National Academy Press; 1995.

8. World Health Organization. Health benefits of family planning. Geneva: WHO; 1994.

9. Chandra A, Martinez GM, Mosher WD, Abma JC, Jones J. Fertility, family planning, and reproductive health of U.S. women: Data from the 2002 National Survey of Family Growth. National Center for Health Statistics. Vital Health Stat. 2005;23(25).

10. Casterline JB, El-Zanatay F, El-Zeini LO. Unmet need and unintended fertility: Longitudinal evidence from upper Egypt. Int Fam Plan Perspect. 2003;29(4):158-166.

11. Blanc AK, Curtis SL, Croft TN. Monitoring contraceptive continuation: Links to fertility outcomes and quality of care. Stud Fam Plann. 2002;33(2):127-40.

12. Jain A. Should eliminating unmet need for contraception continue to be a program priority? Int Fam Plan Perspect. 1999:25(suppl): S39-43, S49.

13. Adetunji JA. Unintended childbearing in developing countries: Levels, trends, determinants. DHS Analytical Reports No. 8. Calverton, MD: Macro International Inc.; 1998.

14. Westoff CF. Unmet need at the end of the century. DHS Comparative Reports No. 1. Calverton, MD: Macro International Inc.; 2001.

15. Westoff CF. New estimates of unmet need and the demand for family planning. DHS Comparative Reports No. 14. Calverton, MD: Macro International Inc.; 2006.

16. Ali M, Cleland J. Determinants of contraceptive discontinuation in six developing countries. J Biosoc Sci. 1999;31(3):343-60.

17. Curtis SL, Blanc AK. Determinants of contraceptive failure, switching, and discontinuation: An analysis of DHS contraceptive histo- ries. DHS Analytical Reports No. 6. Calverton, MD: Macro International Inc.; 1997.

18. Ali M, Cleland J. Contraceptive discontinuation in six developing countries: a cause-specific analysis. Int Fam Plan Perspect. 1995;21(3):92-7.

19. Khan MA. Side effects and oral contraceptive discontinuation in rural Bangladesh. Contraception. 2001;64(3):161-7.

20. Blanc AK. The effect of power in sexual relationships on sexual and reproductive health: An examination of the evidence. Stud Fam Plann. 2001;32(3):189-213.

21. Universidad del Valle de Guatemala, CDC Division of Reproductive Health. Guatemala Encuesta Nacional de Salud Materno Infantil, 2002. Informe final. Ciudad de Guatemala: Universidad del Valle; 2003.

22. Strickler JA, Magnani RJ, McCann G, Brown LF, Rice JC. The reliability of reporting of contraceptive behavior in DHS calendar data: Evidence from Morocco. Stud Fam Plann. 1997;28(1):44-53.

23. Steele F, Curtis SL, Choe M. The impact of family planning service provision on contraceptive dynamics in Morocco. Stud Fam Plann. 1999;30(1):28-42.

Manuscript received on 23 May 2007. Revised version accepted for publication on 20 February 2008.
RESUMEN

\section{Asociación entre la suspensión en el uso de anticonceptivos y las intenciones de embarazo en \\ Guatemala}

Objetivos. Determinar si la suspensión del uso de anticonceptivos (SUA) está asociada con embarazos concebidos antes de lo deseado (inoportunos) o no deseados.

Métodos. Se usaron los datos de la Encuesta Nacional de Salud Materna e Infantil en Guatemala de 2002. Los embarazos registrados entre los tres años previos a la encuesta (desde abril de 1999) y el final de la misma (noviembre de 2002) se clasificaron como deseados, inoportunos o no deseados. La variable independiente principal fue si la mujer había usado algún anticonceptivo en los 12 meses previos al embarazo y, en ese caso, la razón de la SUA (para lograr un embarazo u otra razón). Mediante el análisis logístico polinominal se determinó el grado de asociación entre la SUA y el tipo de embarazo resultante.

Resultados. Uno de cada cinco embarazos inoportunos y uno de cada seis embarazos no deseados sucedieron a la SUA por razones ajenas al deseo de un embarazo (por ejemplo, fallas o efectos secundarios del anticonceptivo, o consideraciones de salud). Se encontró una asociación directa y significativa entre la SUA por razones ajenas al deseo de quedar embarazada y los embarazos clasificados como inoportunos (coeficiente $=2,15$; error estándar $=0,27)$ o no deseados $(2,68 ; 0,37)$, en contraste con los embarazos deseados. Las mujeres que suspendieron el uso de anticonceptivos por razones ajenas al deseo de un embarazo presentaron una mayor probabilidad de considerar sus embarazos inoportunos o no deseados que las mujeres que no emplearon medios anticonceptivos en el año previo a su embarazo.

Conclusiones. Es necesario promover el uso continuado de los anticonceptivos. Los programas deben hacer un mayor esfuerzo para reducir las fallas de los anticonceptivos, informar mejor sobre los efectos secundarios y aclarar las preocupaciones sanitarias que puedan llevar a la SUE. A fin de reducir el número de embarazos no programados, se deben identificar y captar a las mujeres que no usan anticonceptivos y quieren demorar o evitar un embarazo.

Palabras clave Anticoncepción, embarazo no planeado, embarazo no deseado, Guatemala. 